\title{
People, planet and profits: the case for greening operating rooms
}

\author{
Yoan Kagoma MD, Nathan Stall MD, Edward Rubinstein MSc CEM, Douglas Naudie MD
}

$\mathrm{O}$ ver the past 40 years, the health care industry has undergone radical changes in the types of products it uses and its waste disposal practices. ${ }^{1,2}$ In the 1980 s, concerns about the spread of blood-borne diseases prompted a shift from reusable to single-use devices, resulting in increases in waste production. ${ }^{3}$

The most recent environmental data on health care in Canada show that in 2008 the sector generated about $1.46 \%$ of Canada's total greenhouse gas emissions and in 2001 was a source of $1 \%$ of total solid waste. ${ }^{4.5}$ Canadian hospital activities were the second most energy-intensive activity in the commercial and institutional sector in 2008, consuming the equivalent annual energy of 440000 Canadian homes. ${ }^{6,7}$ In 2007, US health care facilities contributed $8 \%$ of total greenhouse gas emissions, disposed of more than 4 billion pounds $(1 \mathrm{lb}=$ $0.45 \mathrm{~kg}$ ) of waste and were the second-largest contributor to landfills after the food industry. ${ }^{89}$

Few Canadian hospitals have published their ecological footprints (a calculation of the bioproductive land and water required to sustain a population). However, in 2001, Lions Gate Hospital in Vancouver, British Columbia, reported a footprint of 2841 hectares (ha) or 719 times its actual area. ${ }^{10}$ In 2006, London Health Sciences Centre in London, Ontario, reported a footprint of 63074 global hectares or about 384 times its actual area. ${ }^{11}$

It is ironic that our efforts in hospitals to improve the health of patients contribute detrimentally to the health of the ecosystem. In 2009, the World Health Organization emphasized that hospitals have responsibilities in making health care more sustainable. ${ }^{12}$

\section{The case for greening operating rooms}

Although operating rooms occupy a proportionally smaller physical area of hospitals, they are estimated to generate $20 \%-33 \%$ of total waste produced in hospitals. ${ }^{13,14}$ Waste from the operating room often undergoes high-energy processing to make it safe for disposal. In fact, a single operation may produce more waste than a family of 4 produces in a week. ${ }^{15}$ A study by Stall and colleagues estimated that total knee replacements in Canada in 2008-2009 produced the equivalent landfill waste of 2000 garbage trucks by volume. ${ }^{16}$

In 2002-2003, operating rooms represented $5.9 \%$ of hospital budgets in Canada, and in 2011, Canadian hospitals accounted for $29.1 \%$ ( $\$ 58.4$ billion) of national expenditure on health care or about $3.4 \%$ of the 2011 national gross domestic product. ${ }^{17}$ Estimates suggest that $47 \%-56 \%$ of operating room budgets are dedicated to supplies and materials. ${ }^{18,19}$

Operating rooms pose a particular challenge to waste management because of the need for absolute sterility. Fortunately, technologies and waste-reduction strategies have emerged that satisfy the "triple bottom line" (people, planet and profits), by reducing health care costs and environmental effects without compromising patient care..$^{20}$ In this analysis, we present these initiatives with the aim of increasing awareness and stimulating debate.

We reviewed studies and articles describing the environmental effects of practices in hospitals and operating rooms. Using a predefined search strategy (Appendix 1, available at www .cmaj.ca/lookup/suppl/doi:10.1503/cmaj.112139 /-/DC1) we retrieved 138 articles, of which 65 were used in the analysis.

\section{The 5 R's}

The fundamental principles of decreasing waste in the operating room are the same as the cornerstone strategies of waste minimization: reduce,
Competing interests: Yoan Kagoma, Nathan Stall and Douglas Naudie are founding members of Operation Green, a nonprofit organization that donates unused medical supplies to the developing world. Douglas Naudie declares he or his institution have received funds from Smith \& Nephew, Stryker and DePuy. None declared by Edward Rubinstein.

This article has been peer reviewed.

\section{Correspondence to: \\ Yoan Kagoma, \\ ykagoma2012@meds.uwo.ca}

CMAJ 2012. DOI:10.1503 /cmaj.112139 
reuse and recycle. Recently, experts have suggested the addition of 2 extra R's - rethink and research. ${ }^{21}$ These principles are discussed below and outlined in Figure 1.

\section{Reduce}

Proper waste segregation

Waste from the operating room requires segregation into separate waste streams, with normal solid waste (requiring landfilling) and biohazard or regulated medical waste (requiring highenergy processing) comprising the major streams. The disposal cost of biohazard waste is estimated to be 8 times that of normal solid waste (\$963 v. $\$ 121$ per ton [1 ton $=0.91$ metric ton]). ${ }^{22,23}$

As much as $85 \%$ of hospital waste is nonhazardous solid waste. ${ }^{2,24}$ Unfortunately, 50\%-85\% of waste that should be disposed of as solid waste is actually disposed of as biohazard waste. ${ }^{25}$ The same improper disposal of waste can be seen in the operating room, where one case study

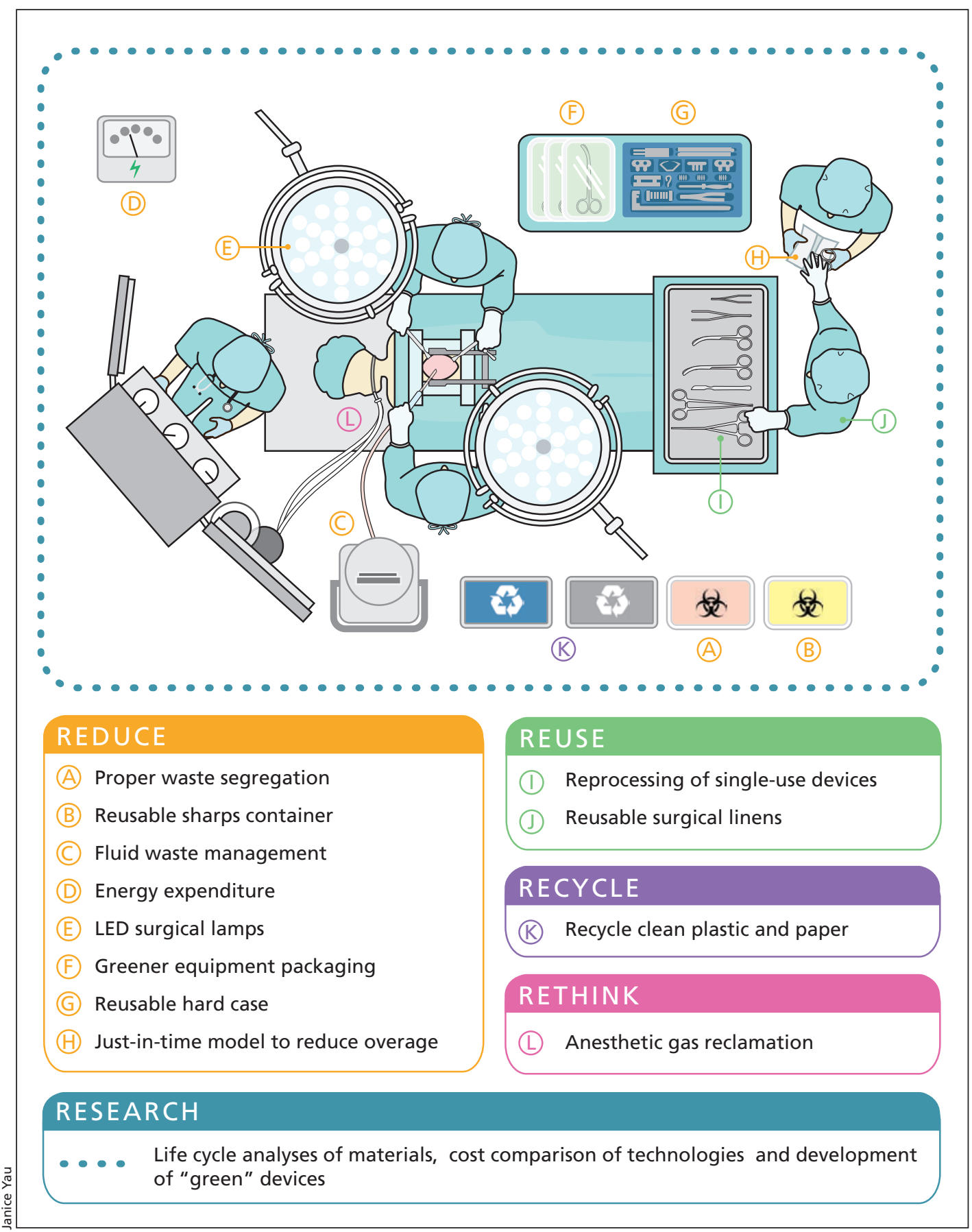

Figure 1: Visualizing the 5 R's: reduce, reuse, recycle, rethink and research. LED = light-emitting diode. 
reported that up to $92 \%$ of discarded biohazard waste may be nonhazardous. ${ }^{3}$ Expert opinion suggests that biohazard waste should constitute no more than $15 \%$ of an institution's total waste stream. ${ }^{26}$ Inappropriate disposal is largely due to a lack of awareness among health care workers on what constitutes biohazard waste. ${ }^{2,25}$

Inappropriately segregated waste increases the amount of waste that requires costly highenergy processing. These processes, which include autoclaving and incineration, have detrimental effects on the environment (see Alternatives to incineration in the Rethink section).

Health care facilities can promote better waste segregation in the operating room by improving access to regular waste receptacles and by educating all perioperative staff about what waste specifically necessitates biohazardous disposal. ${ }^{26}$

The Magee-Womens Hospital of UPMC (University of Pittsburgh Medical Center) in Pennsylvania targeted proper waste segregation and, in 2010, decreased biohazard waste from operating rooms by $47 \%$ with associated savings of more than $\$ 89000 .^{22}$ Experts state that proper waste segregation in the operating room may have the single greatest impact on costs related to waste disposal. ${ }^{14}$

\section{Fluid waste management}

A single surgery may produce up to $12 \mathrm{~L}$ of fluid waste, and a typical operating room generates up to 2 tons of fluid waste each month. ${ }^{27}$ Fluid disposal in the operating room traditionally occurs by pouring fluids into wastewater streams, collecting fluids in surgical suction canisters and disposing of them as biohazard waste, or mixing the fluids with solidifiers with subsequent disposal in the regular waste stream. Surgical suction canisters are estimated to include up to $25 \%$ of biohazard waste from operating rooms. ${ }^{27,28}$

Manual disposal of fluids into wastewater is an occupational hazard as it exposes health care workers to infectious fluids through splashes and aerosolization..$^{28}$ Closed collection systems, which collect fluids at the time of their creation and then directly discharge them into the sanitary sewer, have been shown to reduce workplace exposure while facilitating fluid disposal..$^{22} \mathrm{Al}$ though these systems require an upfront capital expenditure of about US\$5000, they can dramatically reduce the amount of infectious waste requiring high-energy processing. ${ }^{27}$ In 2010, the Good Samaritan Hospital in Suffern, New York, was able to divert more than $250000 \mathrm{lb}$ of fluid waste at a savings of more than $\$ 85000{ }^{22}$

\section{Reusable sharps containers}

Disposal of sharps within the operating room commonly occurs in single-use protective con- tainers. Reusable sharps containers produce less waste and have lower costs over their lifespan. ${ }^{22}$ These containers are processed off-site and returned ready for reuse. The University of Maryland Medical Center in Baltimore, Maryland, reported annual savings of $\$ 70000$ after transitioning to reusable sharps containers. ${ }^{29}$

\section{Energy expenditure}

Operating rooms are areas of high energy intensity because of stringent regulations regarding air circulation, humidity, lighting and temperature. These measures are important for patient safety; however, operating rooms are unoccupied as much as $40 \%$ of the time. ${ }^{30}$ Modifying these requirements based on usage represents an opportunity to reduce energy expenditure. ${ }^{30}$ The Providence St. Peter Hospital in the state of Washington reduced use of energy in its operating room by reducing its ventilation system output by $60 \%$ during unoccupied times. ${ }^{22}$

For many years, halogen lamps have been the standard for surgical lighting; however, lightemitting diodes (LEDs) produce improved colour rendering with up to a $49 \%$ reduction in energy load. ${ }^{31}$ These lights also decrease radiant energy, which reduces the amount of energy needed to cool the operating room.

\section{Medical equipment packaging}

Up to $80 \%$ of solid waste derived from a single operation is generated before a patient enters the operating room..$^{32} \mathrm{~A}$ major contributor to this waste is plastic packaging, with many surgical products packaged in large containers and double-wrapped. Hospitals could therefore consider partnering with industry to promote greener packaging practices.

Another major contributor to waste is blue sterile wrap, a polypropylene plastic that is used to cover surgical instruments during sterilization and maintain sterility during storage. This wrap contributes $19 \%$ of the total waste from operating rooms and is associated with substantial disposal costs. ${ }^{33}$ Blue sterile wrap is not reusable, and hospitals can reduce consumption by switching to reusable hard metal cases. ${ }^{33}$ These cases protect instruments during transport, facilitate organization of equipment and are more resistant than blue sterile wrap to breakages in sterility. ${ }^{22}$ At the MetroWest Medical Center in Framingham and Natick, Massachusetts, a transition to these cases reduced disposal of blue sterile wrap by $5606 \mathrm{lb}$ with a cost savings of $\$ 29843 .^{22}$

Alternatively, hospitals can partner with industrial manufacturers that use polypropylene as a feedstock for other retail products. ${ }^{33}$ Over a 3-year period, the Sinai Hospital in Baltimore, Maryland, recycled $16230 \mathrm{lb}$ of blue sterile wrap. ${ }^{34}$ 


\section{Reducing overage}

The term "overage" describes surgical inventory that is readied for surgery but is ultimately not used and thereby wasted. ${ }^{35}$ To promote efficiency in the operating room, many hospitals use industry-prepared surgical packs. Unfortunately, these packs often contain items that are not routinely used because of surgeons' personal preferences about equipment. ${ }^{3}$ Nonetheless, once the outer packaging is opened, all included items are considered exposed to the surgical field and therefore must be discarded. A 1997 study projected that overage from 14719000 surgical procedures performed in the United States in 1993 resulted in a loss of $\$ 125000000 .^{35}$

Hospitals can reduce overage by working with suppliers to individualize surgical packs based on institutional practice or have the hospital's own central supply services assemble custom surgical packs. ${ }^{3}$ At the University of Minnesota Medical Center in Minneapolis, Minnesota, reformulation of surgical kits yielded annual savings of $\$ 81278$ and waste reduction of $5332 \mathrm{lb}^{22}$ Elsewhere, a targeted educational program and surgical pack redesign resulted in overage reductions of $45 \%$ per surgical case. ${ }^{35}$ Operating rooms could also consider redesigning their supply system to a "just-in-time" industrial model whereby surgical supplies for nonemergencies are delivered only when needed. ${ }^{36}$

Finally, several donation projects have emerged that collect overage materials and distribute them as aid to the developing world. These projects include the pilot program REMEDY (recovered medical equipment for the developing world) at Yale University (www.remedyinc.org) ${ }^{37}$ and Operation Green, a program started at Western University in London, Ontario (www.operationgreen.ca).

\section{Reuse}

\section{Reprocessing of medical equipment}

Reprocessing involves making single-use devices suitable for reuse ${ }^{38}$ and can occur within a hospital or off-site by a third party. ${ }^{39}$ Commonly re processed items include saw blades, trocars and catheters. In Canada, a survey of 398 hospitals reported that $28 \%$ reprocess single-use devices. ${ }^{40}$ Private companies in the US currently reprocess more than 100 types of single-use devices. ${ }^{41}$

Reprocessing medical equipment substantially reduces waste production and disposal costs, and allows hospitals to "buy back" re processed medical devices at a $50 \%$ cost reduction. ${ }^{42}$ In 2008 , a leading reprocessing service reported that hospitals using its service saved US\$138 142000 and $4300000 \mathrm{lb}$ of waste. ${ }^{42}$ The Kaiser Permanente health care system in the
US reduced waste by $208200 \mathrm{lb}$ and saved $\$ 5.7$ million in purchasing costs through its reprocessing program in $2008 .^{43}$

\section{Reusable surgical linens}

Surgical linens, which include gowns, drapes and table covers, contribute $2 \%$ of all hospital waste $^{44}$ These items are available as single-use or reusable products, with about $80 \%$ of hospitals in the US using single-use gowns. ${ }^{44}$

Early life cycle analyses comparing single-use and reusable linens - which must be laundered - were conflicting when comparing environmental impact, cost and infection control. ${ }^{45}$ However, a more recent life cycle analysis has shown the environmental and financial superiority of reusable surgical linens. ${ }^{46}$ This 2010 study showed that surgeons prefer reusable products as a result of their increased comfort, ease of use and superior protective properties. ${ }^{46}$ In 2010, the University of Maryland Medical Center avoided disposal of $138748 \mathrm{lb}$ of waste and saved about \$38 000 in hauling costs by using reusable surgical linens..$^{22,46}$

\section{Recycle}

During the surgical set-up, a large volume of highquality recyclable plastics is generated, and these items can be easily recycled by installing collection containers. The hauling costs for recyclable plastics are nearly half that of solid waste disposal (US\$68 v. US\$121 per ton). ${ }^{22}$ Institutions can also negotiate rebates for recycled plastics. ${ }^{22}$

Paper, cardboard and metal products can be easily collected for recycling in the operating room. Some hospitals have achieved recycling rates as high as $40 \%$ of total waste with substantial savings achieved through reduced hauling costs and revenues from industrial recyclers. ${ }^{25}$

\section{Rethink}

\section{Alternatives to incineration}

Incineration of medical waste is a means to reduce the volume of waste and destroy biohazardous materials. ${ }^{47}$ However, this process produces environmental contamination by releasing nitrous oxide, as well as known carcinogens including polychlorinated biphenyls, furans and dioxins. Exposure to these compounds has been linked with decreased fetal weights, hormonal alterations, infertility, and the acidification of soil and aquatic environments. ${ }^{2,48,49}$

A targeted strategy to close incinerators as well as stringent emissions targets saw annual Canadian dioxin and furan emissions decrease by $87 \%$ between 2000 and $2005 . .^{50}$ Nonetheless, as of $2007,85 \%$ of dioxin and furan emissions in Canada remained attributable to 36 active hospi- 
tal incinerators..$^{50}$ These institutions should consider transitioning to alternative treatment processes for medical waste, including thermal, chemical, irradiative or biological approaches. ${ }^{51}$

\section{Anesthetic gases}

Only $5 \%-20 \%$ of delivered anesthetic gases are actually metabolized by a patient, ${ }^{52,53}$ while the remaining gases are vented into the atmosphere where their global warming potential is 2000 times that of carbon dioxide. ${ }^{52,54}$ In 2005, anesthetic emissions at 1100 Canadian hospitals were estimated at more than 1.1 million tons of carbon dioxide equivalent, which is the same as the total annual emissions of 68000 Canadians. ${ }^{52}$

Anesthetic collection services have emerged that capture, reprocess and resell vented gases at reduced costs to partnering hospitals. ${ }^{54,55} \mathrm{~A}$ recovery system was used in 21 operating rooms at Sunnybrook Health Sciences Centre in Toronto, Ontario, and over a 5-year period, the hospital prevented the equivalent annual emissions of 205 automobiles. ${ }^{56}$

\section{Environmental stewardship teams and waste audits}

Environmental stewardship teams can help coordinate greening efforts by improving awareness, changing attitudes and coordinating environmentally preferred purchasing programs. These programs purchase products that have reduced effects on the environment and are costeffective. ${ }^{3}$ Importantly, hospitals are uniquely positioned to drive the market for more sustainable products as a result of their considerable purchasing power. ${ }^{21}$

Environmental stewardship teams can also coordinate waste audits. A waste audit is a quantitative and qualitative method used to assess waste management practices and target areas for improvement. ${ }^{2,26}$ Recently, the Ontario Hospital Association established the Green Hospital Champion Fund, which will subsidize up to $80 \%$ of the costs for a waste audit. Ninety audits are currently supported by this program. ${ }^{57}$

\section{Research}

Given that the most recent data on greenhouse gas emissions and solid waste from hospitals date back to 2008 and 2001, respectively, the need for research is clear. ${ }^{4,5}$ Despite the emergence of new approaches and technologies, quality-improvement studies examining the effects of these initiatives are sparse. Many studies are not independently verified and may be biased by industry. ${ }^{1}$ Bringing a rigorous and evidencebased approach to this research is important for the legitimacy of the findings. Particularly useful would be updated statistics on the environmental effects of health care activities, life cycle analyses of materials, cost comparisons and development of devices that minimize environmental effects while maintaining quality of care.

\section{Overcoming challenges}

At a time when Canadian hospitals and health care personnel are often working above capacity, one may argue there is little room for greening efforts. With nearly $40 \%$ of hospitals in Ontario facing deficits, administrators must allocate funds for delivery of services and availability of beds rather than invest in greening initiatives. ${ }^{58}$

However, in an effort to cut costs, many health care facilities are being asked to improve efficiency. Our analysis has shown that greening initiatives in the operating room are easily implemented, require low capital investment, have a short payback period and can generate substantial cost savings. ${ }^{58}$

Finally, considering that $48 \%$ of Canadians do not believe global warming is a result of human activities, ${ }^{59}$ the psychological barriers to greening operating rooms are strong. Successful efforts must therefore begin by changing institutional attitudes. ${ }^{60}$ This could start with the development of environmental awareness campaigns and education of health care trainees about the environmental impacts of health care provision.

\section{A greener future}

Canadian hospitals provide high-quality care through a widely accessible and publicly funded health care system. However, the provision of health care is not benign, and many of the interventions used to save lives affect the environment.

Undoubtedly, hospitals must place priority on patient safety and quality of care; however, we argue that our current trajectory may be altered without compromising either. Many technologies and materials alternatives are available to transition toward more sustainable practices. At a time when policy-makers are searching for innovative strategies to save money, the greening of operating rooms deserves keen attention. Total savings from the greening initiatives highlighted in this article could save institutions millions of dollars and avoid tons of waste and emissions for their communities. ${ }^{61}$

The future is promising as interest in greening health care continues to grow through organizations such as the Canadian Association of Physicians for the Environment, Health Care Without Harm, Canadian Coalition for Green Health Care and Practice Greenhealth. The latter organization 
established the Greening the Operating Room Initiative, which provides collaborating hospitals with data, tools and resources to transition to more sustainable operating room practices. ${ }^{62}$ Recognizing the importance of physician leadership, Practice Greenhealth also recently launched the Council for Environmentally Responsible Surgery. ${ }^{63}$ Ensuring the long-term environmental sustainability of our health care system will require collaboration.

The continued lack of awareness about the effect that the provision of health care has on the health of the ecosystem represents a very real risk to the long-term sustainability of our health care system and our planet. As patient advocates, community leaders and scientists, physicians are wellpositioned to spearhead research and multidisciplinary initiatives focused on more sustainable health care practices. The operating room is a disproportionate contributor to health care waste and represents a high-yield target for change.

\section{References}

1. Nussbaum GF. Alternative waste management strategies. Perioper Nurs Clin 2008;3:63-72.

2. Melamed A. Environmental accountability in perioperative settings. AORN J 2003;77:1157-68.

3. Laustsen G. Reduce-recycle-reuse: guidelines for promoting perioperative waste management. AORN J 2007;85:717-22.

4. Canada's GHG emissions by sector, end-use and sub-sector including electricity-related emissions. Ottawa (ON): Natural Resources Canada, Office of Energy Efficiency; 2008.

5. Hancock T. Doing less harm: assessing and reducing the environmental and health impact of Canada's health care system. Branchton (ON): Canadian Coalition for Green Health Care; 2001.

6. 2007 survey of household energy use - summary report. Ottawa $(\mathrm{ON})$ : Natural Resources Canada, Office of Energy Efficiency; 2010.

7. Statistics on the Commercial and Institutional Sector in Canada. In: 2008 commercial and institutional consumption of energy survey: summary report. Ottawa $(\mathrm{ON})$ : Natural Resources Canada, Office of Energy Efficiency; 2008.

8. Chung JW, Meltzer DO. Estimate of the carbon footprint of the US health care sector. JAMA 2009;302:1970-2

9. DiConsiglio J. Reprocessing SUDs reduces waste, costs. Mater Manag Health Care 2008; 17:40-42.

10. Germain S. The ecological footprint of Lions Gate Hospital. Hosp Q 2001-2002;5:61-6.

11. London Health Sciences Centre Ecological Stewardship Team London Health Sciences Centre's Footprint. London (ON): London Health Sciences Centre; 2009.

12. Healthy hospitals, healthy planet, healthy people: addressing climate change in healthcare settings. World Health Organization, Health Care Without Harm, Health and Environment Alliance; 2009.

13. Goldberg ME, Vekeman D, Torjman MC, et al. Medical waste in the environment: Do anesthesia personnel have a role to play? J Clin Anesth 1996;8:475-9.

14. Tieszen ME, Gruenberg JC. A quantitative, qualitative, and critical assessment of surgical waste. Surgeons venture through the trash can. JAMA 1992;267:2765-8.

15. Esaki RK, Macario A. Wastage of supplies and drugs in the operating room. Medscape Anesthesiology 2009; Oct. 21. Available: www.medscape.com/viewarticle/710513 (accessed 2011 Dec. 1).

16. Stall NM, Kagoma YK, Bondy JN, et al. A surgical waste audit of five total knee arthroplasties. Can J Surg. In press.

17. Canadian Institute for Health Information (CIHI). National health expenditure trends, 1975 to 2011. Ottawa (ON): The Institute; 2011.

18. Souhrada L. OR and materials: the yin and yang. Mater Manag Health Care 1999;8:18-20.

19. Park KW, Dickerson C. Can efficient supply management in the operating room save millions? Curr Opin Anaesthesiol 2009;22: 242-8.

20. Hindle T. Triple bottom line. The Economist 2009 Nov. 17.
21. Hutchins DC, White SM. Coming round to recycling. BMJ 2009;338:b609.

22. Greening the OR: guidance documents. Reston (VA): Practice Greenhealth 2011. Available: www.c4spgh.org/HCW1 _Presentations/GOR_FullSet_Guidance\%20Docs_Web_042711 .pdf (accessed 2011 Dec. 1).

23. United States Air Force. Medical waste incinerator waste management plan Malcolm Grow Medical Center, Building 1056, Andrews Air Force Base, Maryland. Herndon (VA): Pacific Environmental Services; 2001.

24. Shaner H, McRae G. Eleven recommendations for improving medical waste management. Burlington (VA): The Nightingale Institute for Health and the Environment; 2006

25. Shaner H, McRae G. Invisible costs/visible savings: innovations in waste management for hospitals. Surgical Services Management 1996;2:17-21.

26. Regulated medical waste reduction: 10 steps to implementing a regulated waste reduction plan. Washington (DC): Hospitals for a Healthy Environment; 2010. Available: www.healthcarewaste .org/fileadmin/user_upload/resources/10_Steps_to_Implementing a Regulated_Medical_Waste_Reduction_Plan.pdf (accessed 2011 Jan. 26)

27. Barlow RD. Proper liquid waste disposal mines solid gold bottom line. Healthcare Purchas News 2004;28:60-4.

28. Mathias JM. Safe options for suction canister waste. OR Manager 2004;20:16-8.

29. Saver C. Going green in the OR brings financial, environmental gains. OR Manager 2011;27:1,10-3.

30. Love C. Operating room HVAC setback strategies. Chicago (IL): The American Society for Healthcare Engineering; 2011.

31. Tuenge JR. LED Surgical Task Lighting Scoping study: a hospital energy alliance Project. Richland (WA): United States Department of Energy; 2011.

32. Donaldson K. Save the planet: recycling in the OR. Infection Control Today 2000 July 1. Available: www.infectioncontrol today.com/articles/2000/07/save-the-planet-recycling-in-the-or.aspx (accessed 2011 Jan. 26)

33. Reusable totes, blue wrap recycling and composting. Washington (DC): US Environmental Protection Agency; 2002. Available: www.epa.gov/region9/waste/p2/projects/hospital/totes.pdf (accessed 2011 Jan. 5)

34. Parham JC. Path to green: practice improvement in the OR. AORN J 2011;93:792-5.

35. Rosenblatt WH, Chavez A, Tenney D, et al. Assessment of the economic impact of an overage reduction program in the operating room. J Clin Anesth 1997;9:478-81.

36. Rosenblatt WH, Silverman DG. Cost-effective use of operating room supplies based on the REMEDY database of recovered unused materials. J Clin Anesth 1994;6:400-4.

37. Ariyan S, Rosenblatt WH. Project REMEDY (recovered medical equipment for the developing world): helping our colleagues around the world. Bull Am Coll Surg 1994;79:30-5.

38. Selvey D. Medical device reprocessing: Is it good for your organization? Infection Control Today 2001 Jan. 1.

39. United States Food and Drug Administration. Enforcement priorities for single-use devices reprocessed by third parties and hospitals. Silver Spring (MD): The Administration; 2000.

40. Polisena J, Hailey D, Moulton K, et al. Reprocessing and reuse of single-use medical devices: a national survey of Canadian acutecare hospitals. Infect Control Hosp Epidemiol 2008;29:437-9.

41. United States Food and Drug Administration. Executive summary: survey on the reuse and reprocessing of single-use devices (SUDs) in US hospitals. Silver Spring (MD): The Administration; 2009.

42. Kwakye G, Pronovost PJ, Makary MA. Commentary: a call to go green in health care by reprocessing medical equipment. Acad Med 2010;85:398-400.

43. Hill L. The three legged stool of regulated medical waste reduction. Reston (VA): Practice Greenhealth; 2010

44. Rutala WA, Weber DJ. A review of single-use and reusable gowns and drapes in health care. Infect Control Hosp Epidemiol 2001;22:248-57.

45. European Textile Services Association. ETSA life cycle assessment of surgical gowns. Brussels (Belgium): The Association; 2002.

46. Conrardy J, Hillanbrand M, Myers S, et al. Reducing medical waste. AORN J 2010;91:711-21.

47. Li CS, Jenq FT. Physical and chemical composition of hospital waste. Infect Control Hosp Epidemiol 1993;14:145-50.

48. Singh A, Agrawal M. Acid rain and its ecological consequences. J Environ Biol 2008;29:15-24.

49. Badr O, Probert SD. Environmental impacts of atmospheric nitrous oxide. Appl Energy 1993;44:197-231.

50. Dioxins and Furans Incineration Canada-wide Standards Review Group. Review of dioxins and furans from incineration in sup- 
port of a Canada-wide standard review. Winnipeg (MB): Canadian Council of Ministers of the Environment; 2007.

51. Emmanuel J, Puccia CJ, Spurgin RA. Non-incineration medical waste treatment technologies. Washington (DC): Health Care Without Harm; 2001.

52. Blue-Zone Technologies. Hospital anesthetic gas discharges and the environment: prevent the vent [factsheet]. Mississauga (ON): Canadian Centre for Pollution Prevention; 2005.

53. Langbein T, Sonntag H, Trapp D, et al. Volatile anaesthetics and the atmosphere: atmospheric lifetimes and atmospheric effects of halothane, enflurane, isoflurane, desflurane and sevoflurane. Br J Anaesth 1999;82:66-73.

54. Doyle DJ, Byrick R, Filipovic D, et al. Silica zeolite scavenging of exhaled isoflurane: a preliminary report. Can J Anaesth 2002; 49:799-804.

55. Jänchen J, Bruckner JB, Stach H. Adsorption of desflurane from the scavenging system during high-flow and minimal-flow anaesthesia by zeolites. Eur J Anaesthesiol 1998;15:324-9.

56. Brent P. A greener way to get anesthetized. Globe and Mail [Toronto] 2010 Oct 25.

57. Ontario Hospital Association. Green Hospital Champion Fund Toronto (ON): The Association; 2011. Available: www.oha.com /CurrentIssues/Issues/Green\%20Healthcare/Pages/GreenHospital ChampionFund.aspx (accessed 2011 Dec.).

58. Ueckermann J. Green initiatives in hospitals in Ontario: Is there a business case? Matieland (South Africa): University of Stellenbosch; 2011.

59. Britons question global warming more than Americans and Canadians. Angus Reid Public Opinion 2011 Sept. 12
60. Topf M. Psychological explanations and interventions for indifference to greening hospitals. Health Care Manage Rev 2005;30:2-8

61. Park KW, Dickerson C. Can efficient supply management in the operating room save millions? Curr Opin Anaesthesiol 2009;22: 242-8.

62. Greening the operating room. Reston (VA): Practice Greenhealth; 2011. Available: http://practicegreenhealth.org/initiatives /greening-operating-room (accessed 2011 Jan. 1).

63. Council for environmentally responsible surgery. Reston (VA): Practice Greenhealth; 2011. Available: http://practicegreen health.org/initiatives/greening-operating-room/council-environ mentally-responsible-surgery (accessed 2011 Dec. 11).

Affiliations: From Schulich School of Medicine \& Dentistry (Kagoma, Stall, Naudie), Western University, London, Ont.; the Department of Energy \& Environment (Rubinstein), University Health Network, Toronto, Ont.; and the Department of Orthopaedic Surgery (Naudie), London Health Sciences Centre, London, Ont.

Contributors: All authors contributed to the conceptualization of the manuscript. Yoan Kagoma and Nathan Stall drafted the manuscript, which all authors revised. All authors approved the final version submitted for publication.

Acknowledgements: The authors thank Janice Yau for her original artwork contribution and Jennifer Bondy for her work in conceptualizing this manuscript and comments on early drafts. 